\title{
Formación, tradición y racionalidad: comentarios a mis críticos
}

\author{
Ambrosio Velasco Gómez
}

A

gradezco a Mariflor Aguilar, Carlos Pereda, Carlos Oliva y Raúl Alcalá su amabilidad para leer y comentar mi trabajo "La relevancia del pensamiento de Gadamer en la filosofía: más allá de la modernidad y de la posmodernidad". ${ }^{1}$ Pero sobre todo agradezco la agudeza de sus críticas y sugerencias que me motivan a esclarecer y corregir algunos puntos fundamentales de mi interpretación del pensamiento de Hans-Georg Gadamer. Sirvan estos comentarios míos para continuar el diálogo gadameriano en esta revista que con mucha oportunidad ha organizado Mariflor Aguilar con motivo del cumpleaños centenario de Gadamer. ${ }^{2}$

\section{¿Más allá o más acá de la modernidad?}

En primer lugar quiero destacar el pluralismo de los comentarios críticos, que me ubican al mismo tiempo como simpatizante de la posmodernidad y como defensor disimulado de la racionalidad moderna.

Respecto al riesgo de mi desliz hacia la posmodernidad, Carlos Pereda observa que la reconstrucción del concepto gadameriano de tradición que yo hago tiende a reificarla en un vértigo simplificador que excluye la importancia de los métodos y técnicas de la investigación científica y, en general, de toda crítica ilustrada. De esta manera, la tradición se convierte en un tradicionalismo y la sana crítica a la metodolatría en una peligrosa metodofobia.

${ }^{1}$ Ambrosio Velasco, "La relevancia del pensamiento de Gadamer en la filosofía: más allá de la modernidad y la posmodernidad" en Revista del Colegio de Filosofía. Theoría, núm. 7. México, unAM, Facultad de Filosofía y Letras, diciembre, 1998, pp. 55-66.

${ }^{2}$ Vid. Mariflor Aguilar, "Presentación", en Revista del Colegio de Filosofía. Theoría, núm. 7, pp. 51-54. 
Respecto a mi ubicación como reinstaurador de la Ilustración moderna, Carlos Oliva señala correctamente que el propósito principal de mi artículo es mostrar la relevancia del pensamiento gadameriano para superar el agotamiento de las categorías éticas, epistémicas y políticas de la modernidad, y confrontar al mismo tiempo el nihilismo relativista del pensamiento posmoderno que amenaza toda justificación racional del pensamiento y acción humanos. Sobre el desarrollo de mi argumento para sustentar esta pretensión, Carlos Oliva considera que el problema fundamental radica en que doy a las aportaciones de Gadamer "una sistematicidad propia del discurso moderno" y se pregunta "¿no hay, a tras mano de la pretensión de salir de las aporías que manifiestan la modernidad y la posmodernidad, un relato y una potente retórica que nuevamente nos garantiza la racionalidad de las tradiciones, del presente y, faltaba más, la vigencia del discurso utópico y de la racionalidad histórica?"3

Las críticas opuestas a mi interpretación sobre Gadamer de Carlos Pereda y de Carlos Oliva, tomadas conjuntamente, reflejan precisamente mi propósito de ubicarme a medio camino, o para utilizar el concepto desarrollado por Mauricio Beuchot, ${ }^{4}$ de manera analógica entre el racionalismo metodológico ahistórico de la modernidad y el historicismo relativista propio de la posmodernidad. El problema es que para Carlos Pereda, situado más cerca de la Ilustración moderna, ${ }^{5}$ mi posición está más próxima del extremo posmoderno que del virtuoso punto medio, mientras que para Carlos Oliva, situado más lejos de la Ilustración moderna,${ }^{6}$ me alejo de este punto por pecar de racionalista moderno. Por paradójico que suene, creo que ambos tienen razón y esto me obliga a hacer ciertas precisiones y correcciones. Para ello me basaré en buena medida en las sugerencias que generosamente me hace Mariflor Aguilar, especialmente en lo relativo a dar mayor relevancia al concepto gadameriano de formación y de prestar más atención a la noción de "acontecer de la tradición".

${ }^{3}$ Vid. supra Calos Oliva, "La retórica del más allá", p. 212.

${ }^{4} C f$. Mauricio Beuchot, Posmodernidad, hermenéutica y analogía. México, Miguel Ángel Porrúa/Universidad Intercontinental, 1996.

5 Carlos Pereda presentó recientemente una muy interesante interpretación de Gadamer, desde lo que yo considero una posición próxima a la Ilustración moderna. En este trabajo titulado "Hermenéutica, virtudes epistémicas y poscolonialismo" (manuscrito), Carlos Pereda propone una complementación de las virtudes propias de las metodologías científicas, con las virtudes propias de la hermenéutica. Agradezco a Carlos Pereda que me haya facilitado este manuscrito que espero pronto se publique.

${ }^{6}$ Esta posición de Carlos Oliva se manifiesta en su excelente artículo sobre Gadamer "La permanencia del pasado: lo clásico en el tiempo", en Revista del Colegio de Filosofía. Theoría, núm. 7, pp. 79-98. 


\section{Racionalidad práctica y racionalidad metodológica en la ciencia}

La idea central de la modernidad que rescata mi interpretación de Gadamer es precisamente la de racionalidad. Pero en el pensamiento gadameriano y en destacados filósofos la ciencia, la racionalidad desborda por mucho los alcances de las técnicas y métodos de comprobación y demostración, contraviniendo así una tesis central de la Ilustración moderna, vigente, como dice Carlos Pereda, desde Descartes y Bacon hasta los positivistas lógicos y Popper. Así, pues, no es el caso de que se desprecie la metodología y la lógica, sino que simplemente se reconocen sus límites ${ }^{7}$ y se demanda su necesaria complementación con otro tipo de argumentos de carácter práctico y prudencial. En este sentido, creo que hay una plena coincidencia entre mi interpretación de Gadamer y la tesis de Carlos Pereda de evitar tanto la "metodolatría" como la "metodofobia".

La tesis de que la metodología necesariamente debe de enmarcarse en el ámbito más amplio de la racionalidad prudencial no es una idea exclusiva ni original de Gadamer. Desde principios del siglo xx, Pierre Duhem en su célebre obra El fin y la estructura de la teoría física planteó con claridad y rigor el problema de la subdeterminación empírica de las teorías y, en consecuencia, puso en evidencia las limitaciones de los métodos de contrastación empírica de hipótesis, sea para verificarlas, sea para refutarlas. De hecho la misma evidencia empírica puede lógicamente ser utilizada para corroborar una hipótesis o para refutarla. Por ello la lógica necesita ser complementada con otro tipo de razones que la razón metódica no entiende. Veamos este argumento en la siguiente cita extensa de Duhem:

Cuando ciertas consecuencias de una teoría son golpeadas por la contradicción experimental, sabemos que debemos modificar la teoría, pero tal contradicción no nos indica cómo modificarla. Esto deja al físico la tarea de encontrar por sí mismo el punto débil que afecta a todo el sistema teórico. No existe principio absoluto alguno que dirija esta indagación que diferentes físicos pueden conducir de muy diferentes maneras sin que ninguno de ellos tenga el derecho de tachar a otro de ilógico [...] Eso no quiere decir que no podamos preferir pro-

${ }^{7}$ El reconocimiento cauto y limitado de Gadamer de la relevancia de la metodología se expresa claramente en la siguiente cita: "Quien quiere aprender una ciencia necesita dominar su metodología. Pero sabemos que la metodología por sí misma no ofrece ninguna garantía de éxito y productividad de su aplicación" (Hans-Georg Gadamer, "La universalidad del problema hermenéutico", en Verdady Método II. Salamanca, Sígueme, 1994, p. 220). 
piamente el trabajo de uno de ellos sobre otros. La lógica pura no es la única regla de nuestros juicios; algunas opiniones que se salvan del martillo del principio de no contradicción pueden ser perfectamente no razonables. Estos motivos que no proceden de la lógica pero que no obstante dirigen nuestras preferencias y elecciones, "estas razones que la razón no conoce" y que habla del amplio "espíritu de fineza" y no del "espíritu geométrico" constituye lo que es propiamente llamado buen sentido. ${ }^{8}$

El buen sentido (bon sens) es para Duhem el fundamento de esa racionalidad más amplia que enmarca y complementa a la racionalidad metodológica. Duhem nos dice que el buen sentido se puede desarrollar a través de la confrontación dialógica de las diferentes hipótesis y teorías que presentan diferentes científicos. Para ello se requiere que los mismos científicos superen "la pasión que hace a un científico ser demasiado indulgente con sus propias teorías y demasiado severo con los sistemas teóricos de sus colegas".?

Desafortunadamente esta concepción de la racionalidad científica de Duhem no fue retomada ni por los positivistas ni por sus críticos popperianos. Por el contrario, todos ellos trataron de llenar el vacío que deja la lógica, en el ámbito de las decisiones racionales, con una normatividad metodológica que se aleja mucho de la manera en cómo efectivamente razonan los científicos. Precisamente uno de los grandes méritos de Gadamer es volver a intentar reconstruir la racionalidad con una orientación muy semejante a la del brillante científico y filósofo de principios del siglo pasado. Al igual que Duhem, Gadamer considera que la racionalidad práctica se desarrolla a través del diálogo abierto y plural. Pero además, a diferencia de Duhem, Gadamer se preocupa por explicar el proceso histórico de confirmación del buen sentido. Es precisamente en este punto donde me parece muy relevante retomar la sugerencia de Mariflor Aguilar de vincular el concepto de tradición con el concepto de formación -que con toda razón ella, de manera gentil, y Raúl Alcalá, me reclaman de no haberlo desarrollado adecuadamente en mi artículo.

\section{Formación y sensus communis}

Como bien señala Mariflor Aguilar, la noción gadameriana de formación "designa el proceso mediante el cual los individuos y las culturas inscriben sus

${ }^{8}$ Pierre Duhem, The Aim and Structure of Physical Theory. Nueva York, Atheneum, 1962, p. 212. (Originalmente publicado en francés en 1906.)

${ }^{9}$ Ibid., p. 218. 
preocupaciones particulares en una perspectiva más amplia, siendo así que un individuo o un grupo formado o 'cultivado' no puede ser aquel que se restringe a su mundo propio inmediato, sino aquel que participa del diálogo con los otros de quienes aprende".${ }^{10}$ En este sentido, la formación se refiere a la adquisición y ejercicio de capacidades dialógicas para expandir de manera continua el horizonte de las personas y, a través de ellas, del horizonte mismo de la tradición específica a la que se pertenece. La formación, pues, se refiere tanto a la integración de los individuos a una tradición como a los cambios de la tradición como consecuencia del diálogo que los individuos sostienen al interior de esa tradición y con otras tradiciones. ${ }^{11}$ Esta doble dimensión de la formación está presente en el señalamiento de Gadamer de que "la comprensión debe pensarse menos como una acción de la subjetividad que como un desplazarse uno mismo hacia el acontecer de la tradición”. ${ }^{12}$ (Más adelante volveré sobre la noción de "acontecer de la tradición" a la que se refieren Mariflor Aguilar y Carlos Pereda).

Gadamer vincula el concepto de formación con el de sensus communis, esto es, cierto modo de percibir, sentir y juzgar que es reconocido como razonable por todos los miembros de una comunidad que comparten una misma formación y gracias al cual cada uno de ellos es reconocido como un interlocutor competente:

Y esto es precisamente lo que, siguiendo a Hegel, habíamos destacado como característica general de la formación, este mantenerse abierto hacia lo otro, hacia puntos de vista distintos y más generales. La formación comprende un sentido general de la mesura y de la distancia respecto a sí mismo, y en esta misma medida un elevarse por encima de sí mismo hacia la generalidad. Verse a sí mismo y ver los propios objetos privados con distancia quiere decir verlos como los ven los demás... [Pero] los puntos de vista generales hacia los cuales se mantiene abierta la persona formada no representa un baremo fijo que tenga validez $[\ldots]^{13}$

${ }^{10}$ Vid. supra Mariflor Aguilar, "Hermenéutica y tradición", p. 202.

${ }^{11}$ Sobre este último punto coincido con Raúl Alcalá que Gadamer enfatiza más el diálogo al interior de una tradición que entre tradiciones distintas. Sin embargo, coincido más con la interpretación de Habermas que, a partir del análisis del concepto de traducción de Gadamer, reconoce la posibilidad del diálogo entre tradiciones distintas. Así, al menos implícitamente, Gadamer aceptaría la posibilidad de diálogos intertradicionales. (Cf. Jürgen Habermas, La lógica de las ciencias sociales. México, Rei, 1993.)

${ }^{12}$ H.-G. Gadamer, Verdad y Método I. p. 39.

${ }^{13}$ Ibid., p. 46. 
Gadamer rastrea el uso moderno de sensus communis desde Vico hasta el bon sens de Bergson. Gadamer enfatiza que Vico reivindica la noción antigua de sensus communis en contra de la confianza ciega en el método de la ciencia moderna. "Vico no le discute sus ventajas, sino que le señala sus límites. La sabiduría de los antiguos, el cultivo de la prudentia y la eloquentia, debería seguir manteniéndose frente a esta nueva ciencia y su metodología matemática. El tema de la educación también sería ahora otro: el de la formación del sensus communis". ${ }^{14}$ Así, pues, Gadamer encuentra en Vico un antecedente importante en su crítica a la arrogancia ${ }^{15}$ de la racionalidad metódica de la ciencia moderna.

También resulta muy sugerente la referencia de Gadamer al bon sens de Bergson, no sólo porque, al igual que Vico, lo considera como una "fuente común de pensamiento y voluntad" que ofrece una alternativa crítica a la racionalidad cientificista en el ámbito de la acción, sino también porque constituye un antecedente inmediato que retomaría Pierre Duhem como fundamento de la racionalidad científica misma. Con este último autor que desgraciadamente no analiza Gadamer, el ámbito del sensus communis o del bon sens, se extiende del campo de las humanidades, de la ética y de la política, al de las ciencia naturales. Con ello la racionalidad prudencial, que es propia del buen sentido, se extiende también al ámbito de las ciencias de la naturaleza como un complemento indispensable de las técnicas y métodos científicos.

\section{Acontecer de la tradición y racionalidad}

En este último apartado quisiera responder a las observaciones y sugerencias de Mariflor Aguilar y de Carlos Pereda sobre la expresión "acontecer de la tradición” y con base en ello elucidar un poco más la racionalidad de las tradiciones.

El sensus communis, en cuanto complejo de creencias y criterios socialmente reconocidos como legítimos por una determinada comunidad, es re-

${ }^{14}$ Ibid., p. 50.

15 Sobre la arrogancia de la razón resulta muy pertinente lo que nos dice Carlos Pereda: "Por 'razón arrogante' entiendo una manera de creer, desear, sentir, actuar que se rige por el mecanismo antes expuesto: los desbordes del yo se apoyan en un implacable desdén por el valor del otro y, en general, un tener en menos a todo lo otro. Además, también en la razón arrogante, como en cualquier arrogancia, ese desprecio activo por aquello que no pertenece al espacio de la propia validación se formula de manera más o menos sistemática y se exhibe" (Carlos Pereda, Crítica a la razón arrogante. México, Taurus, 1998, p 14). Contra esta noción de razón arrogante la noción de sensus comunnis resulta un correctivo muy apropiado. En este sentido la noción de racionalidad que Gadamer reconstruye a partir del sensus communis resulta otra forma de criticar a la "razón arrogante" que converge con la crítica de Pereda. 
sultado del proceso de la formación de los miembros de esa comunidad. A través de esta formación la tradición se transmite y adquiere vigencia. Este trasmitir y adquirir vigencia, esta "herencia" es a mi entender una importante dimensión del "acontecer de la tradición", dimensión en la que no se destaca la parte activa de las personas que viven en esa tradición. Pero aun como herencia estoy de acuerdo con Pereda que la tradición no acontece "como cae la lluvia" y no "se impone, como un destino", como dice Mariflor Aguilar. El sensus communis que nos hereda la tradición, aunque tiene fuertes semejanzas de familia, no es idéntica a la Sittlichkeit hegeliana o a la "publicidad" heideggeriana que subyuga toda individualidad, toda iniciativa y creatividad. Por el contrario, la vigencia de la tradición requiere de la actividad de las personas que en ella se forman, se cultivan. Por ello puede decir Gadamer que "Aún la tradición más auténtica y venerable no se realiza, naturalmente, en virtud de la capacidad de permanencia de lo que de algún modo ya está dado, sino que necesita ser afirmada, asumida y cultivada" ${ }^{16}$

Pero, además, hay que recordar que el sensus communis no representa "un baremo fijo" al cual apelamos para justificar racionalmente nuestras creencias y acciones, sino que está en continuo movimiento y transformación, por efecto del mismo ejercicio del sensus communis, esto es, de la confrontación dialógica entre diversos y parciales puntos de vista que se esfuerzan por elucidar y alcanzar el punto de vista general de la comunidad a la que se pertenece. En este proceso de elucidación y adecuación, paulatinamente también se transforma el mismo sensus communis. Tal transformación paulatina constituye la dimensión más activa del acontecer de la tradición, donde las personas se convierten en agentes del cambio de la tradición.

Tenemos, así, que el fundamento racional del sensus communis tiene un doble carácter. Por un lado, consiste en reconocer la autoridad de las creencias y criterios intersubjetivamente compartidos para adecuar los puntos de vista individuales al sensus communis que la tradición nos ha heredado; pero, por otra parte, consiste también en poner en tela de juicio, a través del diálogo plural las creencias y criterios que conforman el sensus communis que hemos heredado. En este sentido, la racionalidad propia de las tradiciones aventaja a la racionalidad metodológica, característica de la Ilustración moderna, pues esta última no es reflexiva, esto es, no es capaz de evaluarse críticamente y transformarse. ${ }^{17}$ Además, el acontecer de la tradición en sus

${ }^{16}$ H.-G. Gadamer, Verdad y Método I, p. 349.

${ }^{17}$ Este cuestionamiento y transformación es más radical si el diálogo no se limita al interior de una tradición, sino que se extiende también al diálogo entre diferentes tradiciones. Desde luego que, en estos casos, las dificultades son mayores pues no se cuenta con un sensus communis compartido por las distintas tradiciones. Deficiencia que 
dos dimensiones de herencia y transformación reflexiva explica la génesis y desarrollo racional de la tradición y, al mismo tiempo, constituye el proceso de desarrollo de la racionalidad del sensus communis de la tradición.

Esta coincidencia entre explicación del acontecer de la tradición y justificación de su racionalidad harían de la propuesta gadameriana una concepción descriptiva y normativa de la racionalidad, lo cual es en nuestros días un envidiable mérito filosófico.

Estoy consciente de que quedan varias críticas y preguntas sin contestar. Por ejemplo, la que hacen Carlos Oliva y Carlos Pereda sobre el hecho de que las tradiciones son también, y, principalmente, el lugar de la dominación y la explotación. Este tipo de crítica es muy afín a la que le hace Habermas a Gadamer, que ha sido excelentemente analizada por Mariflor Aguilar en su libro Confrontación. Crítica y hermenéutica, ${ }^{18}$ por lo que más que extenderme en estos comentarios, recomendaría su lectura. También queda pendiente el reclamo de Raúl Alcalá de que debería tratar el concepto gadameriano de experiencia. No dudo que sea un concepto importante, pero ya que él dedica gran parte de sus comentarios a elucidar tal concepto, me parecería muy conveniente que él desarrollara las pistas que sugiere.

Reitero mi agradecimiento a todos mis colegas que me han motivado a través de sus comentarios a revisar y, espero que también a mejorar mi interpretación del pensamiento de Hans-Georg Gadamer.

puede ser parcialmente subsanada por el trabajo hermenéutico de la traducción. No hay espacio aquí para desarrollar el tema de la traducción. Quisiera tan sólo señalar que tanto Khun como MacIntyre consideran que la interpretación y la traducción pueden ser procesos adecuados para el diálogo entre tradiciones distintas. ( $C f$. Thomas Kuhn, "Conmensurabilidad, comunicabilidad y comparabilidad", en C. Solís, comp., ¿Qué son las revoluciones científicas?. Barcelona, Paidós, 1994, y Alasdair MacIntyre, "Traducción y tradición", en Justicia y racionalidad. Pamplona, EDUNSA, 1994, cap. XIX.)

${ }^{18}$ Mariflor Aguilar, Confrontación. Crítica y hermenéutica. México, unAm/Fontamara, 1998. 